\title{
THE SO-CALLED \\ "MACULO-ANAESTHETIC FORM" OF THE INDIAN CLASSIFICATION OF LEPROSY
}

\author{
By R. Chaussinand \\ Chef du Service de la Lèpre, \\ Institut Pasteur, Paris.
}

The recent publication by DHARMENDra and CHATTERJEE of two articles, almost identical, on the subject of maculo-anaesthetic leprosy 4,5 , compels us to expound our point of view with more details than we did in our publication entitled Classification of Leprosyl.

We should like first to make some remarks on terminology though this has not really a prime importance. Nevertheless, in an international primary classification, the use of dissimilar terms should be avoided as much as possible. Therefore we did write in our article': 'It would be unfortunate to use, as the Indian leprologists wish to do, histological definitions for the tuberculoid and lepromatous forms and the clinical definition of maculo-anaesthetic leprosy for the indeterminate form. And the more so, since certain skin lesions of tuberculoid leprosy and sometimes even lepromatous ones, may equally well be described clinically as maculo-anaesthetic*.' This objection was successful enough to excite the interest of Dharmendra and ChATTERJEe because we had not understood that they gave a strictly clinical meaning to the terms 'tuberculoid' and 'lepromatous'. But whatsoever particular sense these authors want to give those two words, the meaning of 'tuberculoid' and 'lepromatous', whether they wish it or not, is only a histopathological meaning and we do not think it advisable to use a mixture of histopathological and clinical terms to name the principal forms of leprosy in an international classification.

But leaving aside the question of terminology, is it really worthy of interest to include a supplementary maculo-anaesthetic form in the primary classification of leprosy? This might be justified if the result were to allow a correct classifying of the patients. For Dharmendra and Chatterjee the maculo-anaesthetic form is a well defined clinical entity. But, when reading carefully what they write, one finds that neither clinical experience, nor bacteriology, nor immunology enables one to see clearly the difference between a maculo-anaesthetic lesion and an indeterminate macule**. Indeed, in

- There is a mistake on our part since Dharmendra and Chatter Jee maintain the indeterminate form in their classification in which it is grouped with 'Borderline' leprosy under the name of 'intermediate' leprosy. However our mistake has no effect on the remarks concerning terminology.

**We would mention that in this article we are using the terms 'macule' and 'macular' in their strict dermatological sense. 
each of the two groups, the lesions are flat and hypopigmented, they appear to be more or less anaesthetic, Hansen's bacillus may be present or absent and the lepromin reaction may be positive or negative. According to the Table published by these authors the only point which would permit one to distinguish between the two lesions would be that the maculo-anaesthetic lesion is dry and the indeterminate lesion is not dry. We doubt very much whether this would be sufficient to make a differential diagnosis. As to the histopathological picture of the maculo-anaesthetic lesion it appears identical with that of a pretuberculoid indeterminate lesion (presence of infiltrations of epithelioid cells). Therefore it is surprising that among all eminent Indian and foreign clinicians, attending the meeting of the Indian Association of Leprologists, one epidemiologist only, J. A. DoulL, did make the pertinent following objection: "I would point out however that in some parts of the world the maculo-anaesthetic case would be called 'indeterminate', and that therefore it is necessary to provide a sharper differentiation between maculo-anaesthetic and indeterminate than is given in DHARMENDRA's paper"' 6 But is this maculo-anaesthetic form, at least, clearly distinct from tuberculoid leprosy? We do not think so. Indeed Dharmendra and ChATTERJEE admit that maculo-anaesthetic lesions may become erythematous and that their hypopigmentation may be masked by hyperpigmentation*. Now erythema and hyperpigmentation are especially to be seen in regressive tuberculoid macules. On the other hand, these authors place under the heading of 'maculo-anaesthetic' cases who are probably typical tuberculoid patients (hypertrophy of cutaneous nerves corresponding to macules; cold abcess in peripheral nerves). Lastly the maculo-anaesthetic lesion can only be distinguished from the macular tuberculoid lesion by a histopathological examination.

From the above it can be inferred that in fact the maculoanaesthetic form of the Indian classification consists of a mixture of pure indeterminate and pretuberculoid indeterminate cases on the one hand and on the other of macular tuberculoid and regressive tuberculoid cases.

DHARMENDRA and ChATTERJEe consider that the adoption of the maculo-anaesthetic form would help medical auxiliaries to a better classifying of their patients. Personally we are rather sceptical as to the possibility of a correct classifying of patients by most of the medical auxiliaries and that whatsoever may be the classification. Besides we do not understand how it could be easier to class patients suffering from benign leprosy into 'tuberculoid', 'maculo-anaesthetic' and 'indeterminate' instead of just grouping them into 'tuberculoid' (cutaneous lesions more or less elevated or with a surface or a border

* Hypopigmentation 'masked' by hyperpigmentation seems a very curious phenomenon. 
slightly wrinkled) and into 'indeterminate' (smooth cutaneous lesions strictly flat).

But what is more serious still the Indian leprologists themselves seem to have some difficulties in classifying the patients into the maculo-anaesthetic form. Thus, in the course of the discussion on MuKERJEe and GhoSAL's communication: Diagnosis of maculoanaesthetic cases of leprosy, ${ }^{7}$ DHARMENDRA declared: 'Regarding MUKERJEE's paper, the results of the lepromin test in this series do not fit in with the usual findings in such cases. I doubt there is something wrong somewhere. Either the lepromin used has not been properly standardised, or perhaps there is something wrong in the selection of patients, or something else'. 6 It appears likewise that there is a confusion as far as the clinical aspect of this maculoanaesthetic lesion is concerned. Dharmendra and Chatterjee described its surface as perfectly flat, what is chiefly a character of indeterminate lesions. RamanUJAN notes that these macules have sometimes a wrinkled appearance, which is usually attributed to regressive tuberculoid lesions. BROWN, through the lens, has often seen a uniform presence of micropapules, which is generally considered as a characteristic sign of minor tuberculoid leprosy. Lastly MuKerJeE and Ghosal even give the name of 'maculo-anaesthetic' to infiltrated lesions elevated sometimes up to $3 \mathrm{~mm}$., that is to say probably typical tuberculoid lesions. ${ }^{7}$

One is therefore justified in concluding that the addition of a maculo-anaesthetic form to the primary classification of leprosy is not to be recommended. Far from making easier a precise classification of patients the adoption of this new hybrid group would only introduce more confusion into the subject.

To influence favourably the admission by all leprologists of a maculo-anaesthetic form in the classification of leprosy, DHARMENDRA and ChatTerJeE declare 4,5: 'It should be clearly understood that the terms macular tuberculoid (of the Madrid Classification) and maculo-anaesthetic (of the Indian Classification) refer to one and the same type of lesion'. These authors try to strengthen this assertion by denying the macular tuberculoid leprosy of the Madrid classification any tuberculoid character. We do not share in the least that opinion. Really a strictly flat lesion cannot be termed 'macular tuberculoid' unless it shows a histopathological structure of tuberculoid nature. It is therefore absolutely misleading to pretend that 'maculo-anaesthetic' and 'macular tuberculoid' may be considered as synonymous terms.

Personally we are not convinced that there is a dominant need to include a macular tuberculoid variety in the classification of leprosy. This moreover appears clearly from our article Classification of Leprosy ${ }^{1}$. In fact macular lesions which are indisputably tuberculoid, showing neither elevation even partly, nor sign of an anterior 
elevation, are relatively rare. Besides they can only be detected by medical teams including a histopathologist, competent in leprology, since the diagnosis cannot be made through a clinical examination. If it is deemed necessary to range macular tuberculoid leprosy among the secondary classification, the.classifying of the patients belonging to this variety should be only entrusted to teams able to undertake histopathological researches. The others ought to use only the old Havana classification which divided benign leprosy into two types: 'tuberculoid' and 'indeterminate' and only admitted two varieties: 'minor' and 'major' for the tuberculoid type. Lesions thoroughly flat and smooth would be classed into indeterminate leprosy and lesions more or less rising or micropapulous included in tuberculoid leprosy, it being well understood that flat lesions showing a surface or border slightly wrinkled would be considered as regressive tuberculoid lesions. By this procedure macular tuberculoid leprosy could be more thoroughly studied by teams able to diagnose it with certainty whilst physicians who have no histopathologist working with them would not run the risk of introducing great confusion in the variety through including pure indeterminate and pretuberculoid indeterminate cases on the one hand and macular tuberculoid and regressive tuberculoid cases on the other. We also wish to add a few more words about terminology. 'Macular' is a descriptive word, whereas 'minor', 'major' and 'borderline' indicate different degrees of the infection. So if we wish to include this variety in the secondary classification it would be preferable to replace the word 'macular' by a more appropriate term. The adjective 'atypical' might be suitable, since the elevation above the surface of the skin, absent from the macule, is one of the principal clinical characteristics of the tuberculoid cutaneous lesion.

We remain entirely in agreement with the first Expert Committee on leprosy ${ }^{3}$ which stated that the basic criteria of the primary classification of leprosy should be clinical and bacteriological, but that when a scientific study of cases is made immunological and histopathological criteria should be fully used to determine certain subgroups. Now the macular tuberculoid variety is precisely one of these sub-groups.

Lastly we should like to repeat what we wrote in our article Classification of Leprosy': 'But it should always be borne in mind that there are certain intermediate and transitory stages that exist between different forms and even between certain varieties of leprosy, and which can sometimes be detected only by histological examination. In our opinion these intermediate stages cannot be considered as varieties as we describe them and they ought not, except for borderline leprosy, to be taken into account in the secondary classification. Similarly the reactional states, whether of long or short duration, which alter, for good or for ill, the normal course of 
the disease, cannot be classified as different varieties. The use of the terms "pretuberculoid", "tuberculoid reaction", "tuberculoid reactional transformation" 2 , "prelepromatous", "lepromatous reaction" and "erythema nodosum" will permit us to describe these transitory stages of the disease'.

\section{Summary}

The Indian leprologists consider that a supplemental form named 'maculo-anaesthetic' should be introduced in the primary classification of leprosy. In two similar articles DhaRmendra and ChatTerJeE even assert that this form constitutes a clinical entity clearly determined. However when studying these authors' text one notices that neither clinical experience nor bacteriology nor immunology allows one to distinguish with certainty a maculo-anaesthetic lesion from an indeterminate macule, from a macular tuberculoid lesion or from a regressive tuberculoid macule. It is therefore erroneous to pretend that the maculo-anaesthetic form constitutes a clinical entity well defined. On the other hand, histopathology shows that this so-called 'form' is really identical with pretuberculoid indeterminate leprosy which means that it represents an intermediate transitory stage between indeterminate leprosy and tuberculoid leprosy which cannot be incorporated in the classification of leprosy either as a 'form' or as a 'variety'.

To favour the admission of that maculo-anaesthetic form in the classification of leprosy Dharmendra and ChatTerJeE declare that the expressions 'macular tuberculoid' in the Madrid classification and 'maculo-anaesthetic' in the Indian classification have the same meaning and cover the same type of lesion. These authors try to strengthen this assertion in denying the macular tuberculoid leprosy of the Madrid classification any histological tuberculoid characteristic. In our opinion it is quite erroneous to pretend that 'maculoanaesthetic' and 'macular tuberculoid' may be considered as synonymous expressions. For indeed a cutaneous lesion of benign leprosy, rigorously flat, cannot be named 'macular tuberculoid' unless it shows a histopathological structure of an unquestionably tuberculoid nature.

It therefore appears that it is not possible to include this so-called 'maculo-anaesthetic form' in the international classification of leprosy. Far from making easier a precise classification of patients, the adoption of this new hybrid group would only bring more confusion.

\section{References}

1Chaussinand, R., Classification of Leprosy. Lep. Review 1961, 32, 74-81 and Correction, Lep. Review 1961, 32, 215-216.

2Chaussinand, R., Destombes, P. and Bourcart, N. Transformation en lèpre tuberculoide de deux cas de lèpre indéterminée prélépromateuse au cours d'un état de réaction. Int. J. Leprosy 1960, 28, 224-232. 
${ }^{3}$ Comité d'Experts de la Lèpre (ler Rapport). O. M. S. Sér. Rap. techn. 1953, 71.

4DHARMENIRA and ChATTERJEe, S. N. Maculo-anaesthetic Leprosy. Its diagnosis and classification. Lep. Rev. 1962, 33, 106-118.

SDharmentra and ChatTERJEe, S. N. Maculo-anaesthetic Leprosy. Its diagnosis and classification. Leprosy in India 1962, 34, 132-144.

6 Meetings of the Indian Association of Leprologists. Fifth Technical Session. Résumé of discussions. Leprosy in India 1962, 34, 37-40.

7MukerJee, N. and Ghosal, P. Diagnosis of maculo-anaesthetic cases of leprosy. Résumé. Leprosy in India 1962, 34, 36. 